\title{
S10. Psychiatry. Health economics
}

THE ECONOMICS OF MENTAL MEALTH: QUESTIONS AND ANSWERS Jennifer Beecham

Research Fellow, Personai Social Services Research Unit, University of Kent at Canterbury and Lecturer in Mental Health Economics, Centre for the Economics of Mental Health, Institute of Psychiatry, University of London, UK

What do care services cost? This is perhaps the question most clearly identified with economics. Economists, however, would see their area of interest as far wider, including, for example, the measurement of outcomes, the allocation of resources in response to need, the criteria of equity and efficiency, consumer choice and charging, and the analysis of markets.

In the United Kingdom and elsewhere in Europe these are all pressing practice and policy issues, but seldom have they been examined in relation to mental health care. The application of economics to mental health care is young. Economics can provide us with a way of organising our thoughts and of providing data to feed into the decision-making process. This paper will first examine the contributions which economics can make to mental health care by identifying a framework informed by economic theory, for evaluating policy and practice issues. It will then identify key policy-related questions and illustrate how some of these questions have been addressed in research undertaken at the Personal Social Services Research Unit and the Centre for the Economics of Mental Health over the last seven years.
TRENDS IN ACTIVITY AND COSTS IN THE ENGLISH PSYCHIATRIC SYSTEM - IMPLICATIONS FOR COSTEFFECTIVENSS EVALUATION

James Raftery

Wessex Regional Health Authority, Dawn House, Highcroft, Romsey Road, Winchester, SO22 5DH, UK

Although the relative costs of alternative psychiatric care and treatment regimes have been widely studied, these have not been set in the context of trends in the relevant costs. In the UK public expenditure on psychiatric services has risen sharply over the past four decades despite dramatic falls in the number of inpatient places. Spending remains concentrated on inpatient facilities. Increased staff numbers have accounted for most of the increased expenditure. As a result of these contrasting trends, the unit costs of inpatient care have soared. The implications of these trends for contemporary studies of the relative cost effectiveness of psychiatric services are discussed.

Co-operation between psychiatrists, psychiatric epidemiologists and health economists is required in the re-organization of the psychiatric health care system. 
NEED FOR DIFFERENTIATED TREATMENT OF SCHIZOPHRENIC PATIENTS?. A HEALTH ECONOMIC PERSPECTIVE

\section{Povl Munk-Jorgensen}

Department of Psychiatric Demography, Institute for Basic Psychiatric Research, Psychiatric Hospital in Aarhus, Skovagervej 2, DK-8240 Risskov, Denmark.

The reorganization of the psychiatric service system causes severe implications on patient treatment, as well as on allocation of resources to different areas of the psychiatric treatment system. Therefore, a maximum utilization of resources is necessary.

All patients diagnosed schizophrenic at least once during a tive-year follow-up period, first admitted to psychiatric hospitals and wards in Denmark during 1986, were identified from The Danish Psychiatric Central Register. 356 patients fulfilled the criteria. Of these, $27(7.6 \%)$ had been admitted fifteen times or more during the period, and were defined as revolving-door patients. The group of revolving-door patients used $31.0 \%$ of the cohort's total number of admissions and $16.3 \%$ of the cohort's total number of bed days. It is most probable that a large part of this group of patients would profit more from treatment in specialized, long-term wards than from treatment in general psychiatric departments.

1,314 schizophrenic patients hospitalized to psychiatric hospitals and wards in Denmark as at December 31, 1992, were identified from The Psychiatric Central register. $32.9 \%$ of these patients had been hospitalized for one year or more, $19,6 \%$ for three years or more, and in total these patients were defined as long-term patients. A gap of up to 2 days between two periods was accepted in order to correct for e.g. administrative transferrals from one hospital to another, minor weekend leaves etc. This group could probably be treated better or less expensive in a social-psychiatric nursing home.

Co-operation between psychiatrists, psychiatric epidemiologists and health economists is required in the re-organization of the psychiatric health care system.

AN ECONOMIC ANALYSIS OF A NEW MULTIDISCIPLINARY COMMUNITY MENTAL HEALTH TEAM BASED IN PRIMARY CARE

M. G. Jackson, R. Gater, D.P. Goldberg, N. Jennett, K. Lowson Mental Iliness Research Unit, University of Manchester, Withington Hospital Nell Lane, Manchester, Great Britain

Community-based multidisciplinary mental health teams are becoming widespread in British mental health services. We evaluated a new team, comparing it to the established hospital-based service using a modified cost benefit analysis. The new team led to doubling of the treated prevalence rates of psychiatric disorder but no change in the use of inpatient beds. It provided better quality care especially for patients with chronic schizophrenia and was well liked by patients and family doctors. Over the first two years it led to an increase in health service expenditure but no change in the wider cost to society. Inceptions to care were treated at substantially lower per capita cost in their first year in care but this was offset by more patients remaining in care incurring costs in subsequent years. For patients with chronic schizophrenia, the community mental health team led to improved targeting of resources at patients with most needs.

\section{COLLABORATION BETWEEN CLINICAL AND HEALTH ECONOMICS RESEARCH: THE WAY FORWARD? \\ Massimo Moscarelli \\ ARCAP, Via Daniele Crespi 7, 20123 Milano, Italy}

Programs for controlling health care costs and improving the quality of care are going to be developed in some countries, with the further development of health services research and outcomes valuation. The reliable and comprehensive evaluation of the particular health economic consequences of each illness as well as of the health care results and costs implications of treatments needs close, interdisciplinary collaboration between the clinician and the health economist. The production and diffusion of health economic evaluation results is aimed at informing policy makers, providers, consumers, health technology producers, etc. in order to inform and assist choices. This paper will illustrate how closer collaboration between clinicians and health economists can aid the delivery of mental health care services. Illustrations will come from different European countries. 